\title{
Encapsulation of Almond Essential Oil by Co-Extrusion/Gelling Using Chitosan as Wall Material
}

\author{
Capablanca Lucía1, Ferrándiz Marcela1, López Ainhoa² \\ ${ }^{1}$ Biotechnology Research Group, Textile Research Institute (AITEX), Alcoy, Spain \\ ${ }^{2}$ Universitat Politècnica de Valencia (UPV), Campus de Alcoy, Alcoy, Spain \\ Email: mferrandiz@aitex.es, ay_ln@hotmail.com
}

How to cite this paper: Lucía, C., Marcela, F. and Ainhoa, L. (2017) Encapsulation of Almond Essential Oil by Co-Extrusion/ Gelling Using Chitosan as Wall Material. Journal of Encapsulation and Adsorption Sciences, 7, 67-74.

https://doi.org/10.4236/jeas.2017.71004

Received: January 25, 2017

Accepted: March 5, 2017

Published: March 8, 2017

Copyright $\odot 2017$ by authors and Scientific Research Publishing Inc. This work is licensed under the Creative Commons Attribution International License (CC BY 4.0).

http://creativecommons.org/licenses/by/4.0/

\begin{abstract}
Encapsulation confers protection to substances as essential oils from processes like oxidation, evaporation or uncontrolled release. In this study almond oil capsules were obtained by co-extrusion/gelling technique. Chitosan was used as shell material and sodium triphosphate pentabasic as cross linking agent. Different encapsulation process variables were studied: cross-linker concentration, nozzles size and potential. Optical microscopy was used to determine the capsules morphology and degradability tests were performed in order to study capsules degradation over time. Results showed that nozzles size and cross linking concentration are key variables to consider in the encapsulation process. Degradability tests showed rapid weight loss.
\end{abstract}

\section{Keywords}

Chitosan, Almond Oil, TTP, Co-Extrusion/Gelling

\section{Introduction}

Encapsulation is defined as a process in which an active agent (core) is enveloped by a polymeric membrane (shell) to produce capsules in the micrometer to millimeter range, known as microcapsules [1].

We can say that encapsulation is a way to protect the substance to be encapsulated, determining its controlled release. Therefore, encapsulation confers added value to a commercial substance. It allows the generation of new application of products for properties that could not be applied so far [2] [3]. Encapsulation can be used to protect the active agents from oxidation caused by heat, light, moisture and contact with other substances and to prevent the evaporation of volatile compounds. Examples of sensitive compounds to these factors are the 
essential oils, substances responsible for taste, aroma and other functional properties [4] [5].

Co-extrusion/gelling has been a widely used technique in the encapsulation of volatile substances [2] [6]. This technique involves the formation of droplets through a vibration overlay, by passing the solution of the shell material and the active agent through an extruder device, with controlled drip size and speed. These drops fall on a bath containing a solution with the gelling agent, resulting in the formation of capsules [7] [8].

The interest in natural products that have a hydrating and restorative skin activity has increased in recent years. Almond oil (Prunus amygdalus dulcis) is well known to possess these properties and it is widely used in the cosmetics industry [9] [10].

Biopolymers, like proteins and hydrocolloids, are used as encapsulating materials in different applications. Copolymer Chitosan (CS) is an example. CS, poly $(1,4)$-2-deoxy-amido-2- $\beta$-D-glucose (2), is a polycationic biopolymer obtained by alkaline deacetylation of chitin, the main component of the exoskeleton of crustaceans. The main parameters that influence the characteristics of chitosan are the molecular weight (MW) and the degree of deacetylation (DD).

CS is showing interest as encapsulating material as it is a natural resource, biodegradable, non-toxic, biocompatible and inexpensive [11] [12] [13] [14].

The obtention of chitosan capsules is realized by means of ionotropic gelation method. In acid solution, the chitosan- $\mathrm{NH}_{2}$ is protonated to be - $\mathrm{NH}_{3}^{+}$. This molecule interacts with the Thymidine 5 '-triphosphate sodium salt solution (TTP) by ionic interaction to result capsules [15] [16].

The objective of this research is the encapsulation of almond essential oil by co-extrusion/gelling using chitosan as shell material, in order to achieve its protection. Different characterization tests have been used to define the microcapsules obtained.

\section{Materials and Methods}

\subsection{Materials}

Medium molecular weight chitosan with a deacetylation degree of $75 \%-85 \%$ (Sigma Aldrich, Spain) was used as shell material. The core material was an essential oil, in particular, almond oil (Ensencias Lozano, Spain).

Sodium triphosphate pentabasic (STP) (Sigma Aldrich, Spain) was used as a cross-linker material.

\subsection{Methods}

\subsubsection{Emulsion Preparation}

Chitosan solution was prepared with $1 \%$ acetic acid (v/v). The cross-linker agent was prepared at different concentrations 4.0 and $8.0 \mathrm{~g} / \mathrm{L}$ with distilled water.

\subsubsection{Microencapsulation by Co-Extrusion/Gelling}

Capsules were obtained by BUCHI B-390 encapsulator at room temperature (Figure 1). Nozzle sizes were modified as shown in Table 1. 

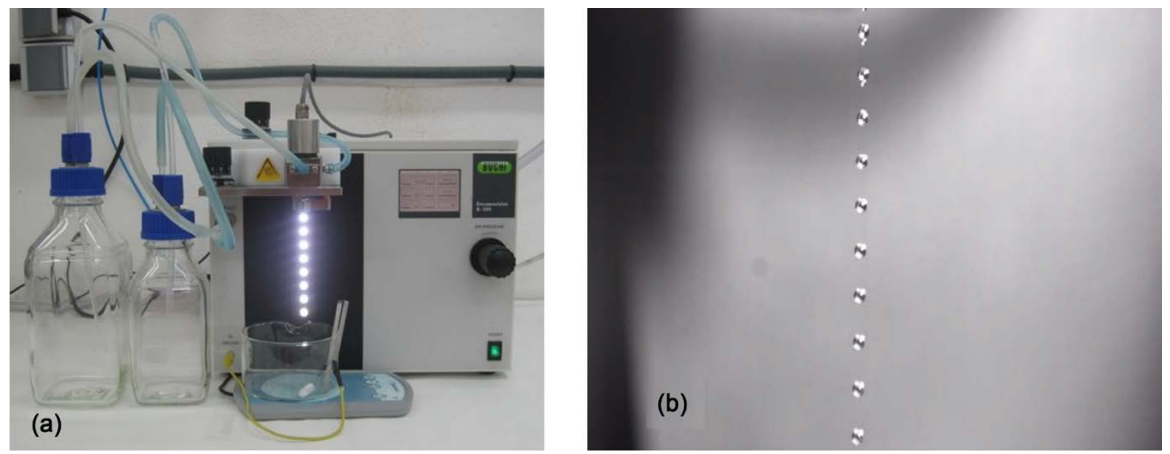

Figure 1. (a) Encapsulator BUCHI B-390. (b) Formation string of beads with the membrane and essential oil.

Table 1. Values of the parameters studied in the encapsulation process.

\begin{tabular}{cccc}
\hline Test number & $\begin{array}{c}\text { Nozzle size } \\
\text { (internal/external) } \mathrm{mm}\end{array}$ & STP concentration $(\mathrm{g} / \mathrm{L})$ & Potential (V) \\
\hline 1 & $0.75 / 0.90$ & 4.00 & 250 \\
2 & $0.75 / 0.90$ & 8.00 & 250 \\
3 & $0.45 / 0.90$ & 8.00 & 250 \\
4 & $0.45 / 0.90$ & 8.00 & 350 \\
\hline
\end{tabular}

Equipment variables are potential $(\mathrm{V})$ and frequency $(\mathrm{Hz})$. These variables were modified until it was perfectly observed the formation of the string of beads. The obtained capsules were filtered and washed three times with distilled water in order to remove any solution of cross linking agent that could be remaining in the capsule wall [7].

\subsection{Experiment Design}

In the research three parameters have been modified in order to optimize the encapsulation process: nozzle size, cross-linker concentration and potential. Chitosan concentration was $1 \%(\mathrm{w} / \mathrm{v})$ and frequency $50 \mathrm{~Hz}$. The performed tests are shown in Table 1.

\section{Characterization Tests}

\subsection{Morphology}

Capsules morphology was studied in an optic microscope Dino-Lite AM4115ZT Edge (Dino-Lite Digital Microscope, Taiwan) with a Dino-Capture Software.

\subsection{Degradability Test}

The aim of this test was to determine the degradation of almond oil capsules.

Almond oil capsules were filtered, and left to air dry during $1 / 2 \mathrm{~h}$ prior to weighing.

A quantity of $0.7 \mathrm{~g}$ of capsules sample were weighed and suspended in $10 \mathrm{~mL}$ of phosphate buffer solution (PBS, $\mathrm{pH}=7.4$ ) in order to analyze the weight loss.

Weight loss was evaluated at $24 \mathrm{~h}, 48 \mathrm{~h}, 72 \mathrm{~h}, 7$ days and 11 days. All assays 
were performed in triplicate, in the absence of light

Results are shown in $\%$ of weight loss, according to the following equation: $\%$ weight loss $=($ final weight - initial weight $) /($ initial weight $) \times 100$.

\section{Results and Discussion}

\subsection{Morphology}

Table 1 shows the encapsulation process variables selected to optimize. These variables were modified in order to obtain a correct string of beads.

The influence of the cross-linker agent concentration was studied, and is presented in Figure 2. Tests corresponding to this variable are Test 1 and Test 2, realized with the encapsulation parameters that are shown in Table 1.

Figure 2(a) and Figure 2(b) corresponding to test 1, show that the crosslinking process didn't occur correctly, so the concentration of $4 \mathrm{~g} / \mathrm{L}$ was discarded. Figure 2(c) and Figure 2(d) corresponding to test 2, show a correct encapsulation of the oil; but the main problem with this test was that the oil was not completely centered in the capsule making it very sensitive to breakage.

One solution to the problem is the modification of the nozzles size; in this research two pairs of nozzles dimension relation (internal/external): 0.75/0.90 and $0.45 / 0.90 \mathrm{~mm}$ were studied. In test 2 , by using the following relation of nozzle size (internal/external): 0.75/0.90, was obtained an asymmetric morphology of the capsules, oval shape, non-spherical as it can be seen in Figure 2(c) and Figure $2(\mathrm{~d})$.

In test 3 , the relation between the nozzles size was changed, meanwhile using the same concentration of chitosan and cross-linker agent. Figure 3(a) shows capsules with correct morphologies. While employing the same conditions as mentioned before, a change in the potential value, $350 \mathrm{~V}$, was studied, in order to observe if it occurs a change in the capsules morphology.
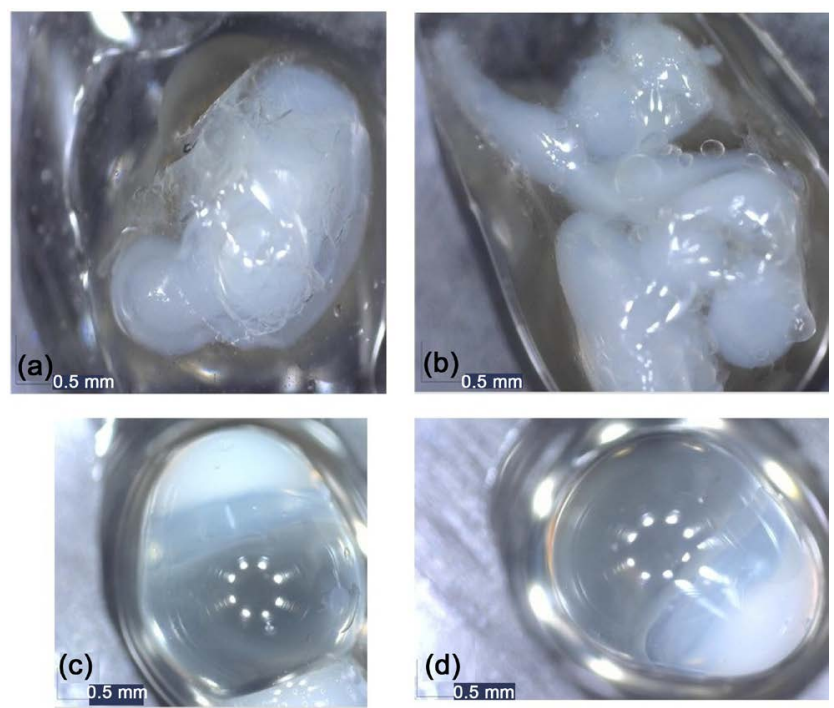

Figure 2. Almond oil capsules obtained in test 1 images (a) and (b), and test 2 images (c) and (d). 

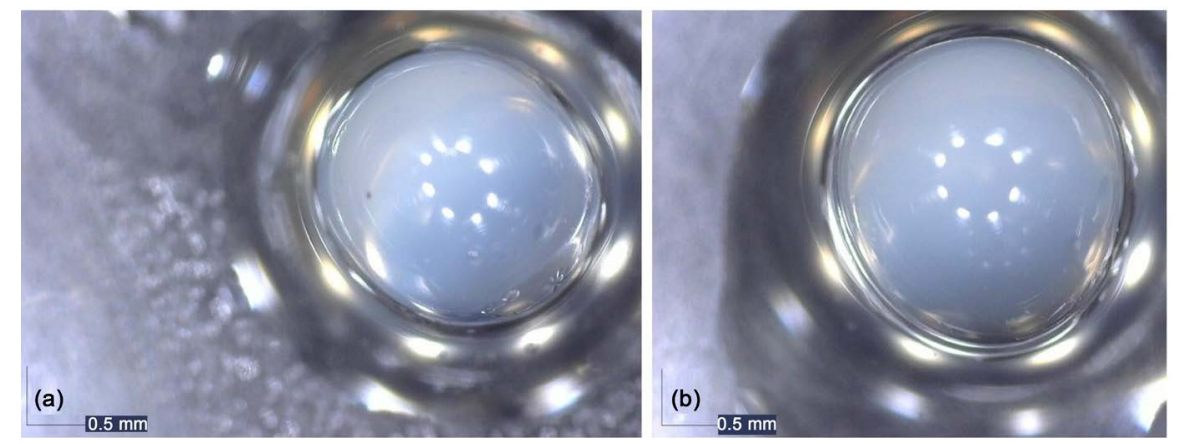

Figure 3. Almond oil capsules obtained under test 3 using $250 \mathrm{~V}$ (a) and test 4 (b) using $350 \mathrm{~V}$.

Table 2. Weight loss of chitosan capsules at different times.

\begin{tabular}{cc}
\hline Degradation time (h) & Weightloss (\%) \\
\hline 0 & $0.0 \pm 0.0$ \\
24 & $73.5 \pm 8.6$ \\
48 & $70.3 \pm 4.5$ \\
72 & $63.3 \pm 3.3$ \\
168 & $70.0 \pm 5.3$ \\
216 & $65.5 \pm 7.1$ \\
264 & $68.1 \pm 4.5$ \\
\hline
\end{tabular}

Figure 3(b) shows that the capsules format was improved, being completely spherical, therefore validating that the potential increase $(350 \mathrm{~V})$ generates improvement in the encapsulation process.

The obtained microcapsules had spherical shapes and because of this, the amount of encapsulated oil was calculated using Equation (1):

$$
V=\frac{4}{3} \cdot \pi \cdot r^{3}
$$

The result obtained was $3.35 \mathrm{~mm}^{3}$.

\subsection{Degradability Test}

Table 2 shows the results of $\%$ weight loss of chitosan capsules at different periods of times.

Results showed that the capsules experimented a rapid weight loss, especially in the first 24 hours when was reached the maximum weight loss. In the other evaluated time intervals, no significant weight increases were recorded. These results are shown in Figure 4.

Figure 5 shows the appearance of different samples at different time intervals of the study. In general, were not observed capsules aggregations which were deposited on the bottom of the test vessel.

\section{Conclusions}

Results show that the co-extrusion/gelling process allows the encapsulation of 


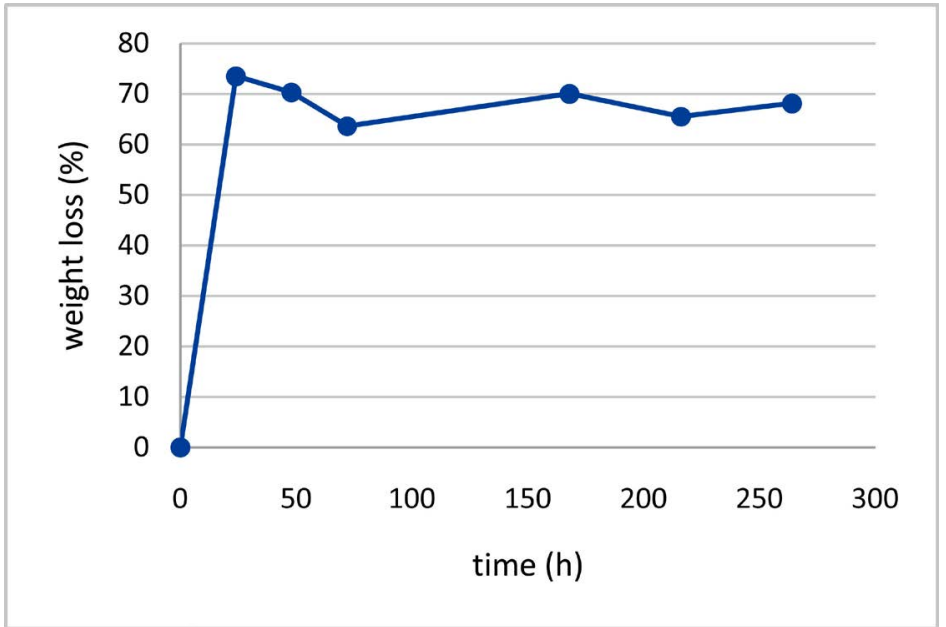

Figure 4. Percentage of weight loss of chitosan capsules.
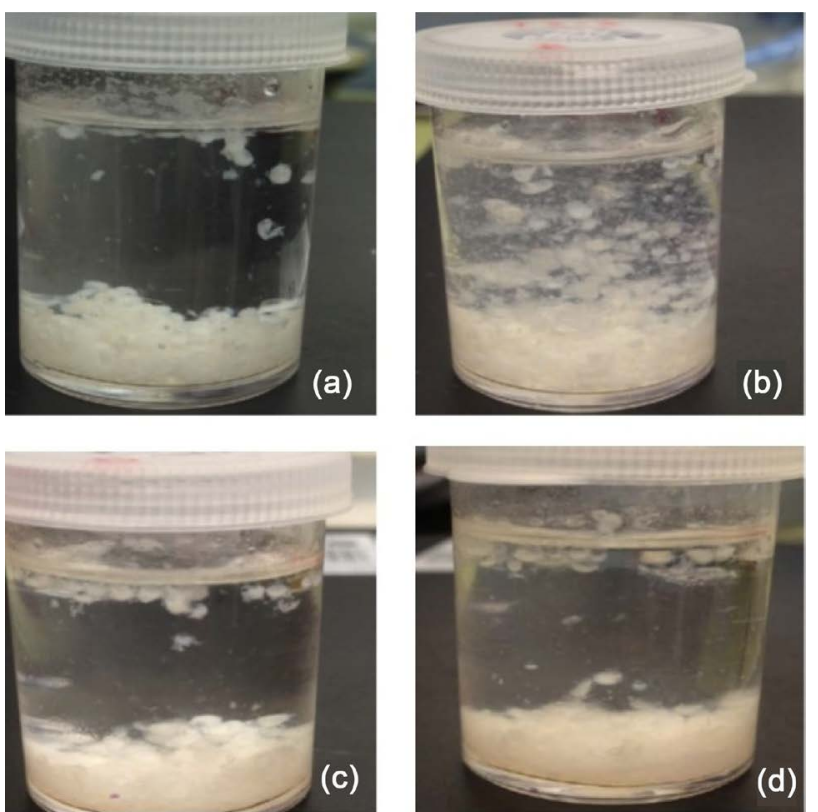

Figure 5. Capsules appearance during study. (a) After 24 h, (b) After 48 h, (c) After 216 h, (d) After $264 \mathrm{~h}$.

almond essential oil using chitosan as wall material. The cross-linker concentration (STP) is important for obtaining stable and nonreversible capsules. The optimal concentration of cross-linker agent is $8.0 \mathrm{~g} / \mathrm{L}$ for a concentration of $1 \%$ (w/v) of chitosan. Concentrations below this value lead to poor crosslinking and therefore the oil capsules do not form.

Nozzle size is another parameter that affects the capsules morphology.

The results reveal that the relation nozzle size (internal/external) of $0.75 / 0.90$ $\mathrm{mm}$ is not suitable for capsule formation, whereas when employing the relation nozzle size (internal/external) $0.45 / 0.90 \mathrm{~mm}$, capsules with suitable morphologies are obtained.

Optical microscopy is a technique that is applied for the validation of the encapsulation of the almond oil. 
A potential increase allows an improvement in the capsules morphology, generating capsules containing almond oil, with spherical shapes.

Degradability tests have shown a rapid loss of weight of chitosan capsules after 24 hours, which may facilitate their application in products which require high degradation levels.

\section{Acknowledgements}

The authors thank for the financial support provided by IVACE (Institut Valencià de Competitivitat Empresarial, Spain) and FEDER (Fondo Europeo de Desarrollo Regional, Europe), and thank for technical and human support provided by Dra. Cristina Canal and Dra. Meritxell Molmeneu from BBT of UPC.

\section{References}

[1] Pulido, A. and Beristain, C.I. (2010) Spray Dried Encapsulation of Ascorbic Acid Using Chitosan as Wall Material. Revista Mexicana de Ingeniería Química, 9, 189195.

[2] Gouin, S. (2004) Microencapsulation: Industrial Appraisal of Existing Technologies and Trends. Trends in Food Science and Technology, 15, 330-347. https://doi.org/10.1016/j.tifs.2003.10.005

[3] Martins, I.M., Barreiro, M.F., Coelho, M. and Rodrigues, E. (2014) Microencapsulation of Essential Oils with Biodegradable Polymeric Carriers for Cosmetic Applications. Chemical Engineering Journal, 245, 191-200. https://doi.org/10.1016/j.cej.2014.02.024

[4] Beristain, C.I., Garcia, H.S. and Vernon-Carter, E.J. (2001) Spray-Dried Encapsulation of Cardamom (Elettaria cadamomum) Essential Oil with Mesquite (Prosopis juliflora). LWT-Food Science and Technology, 34, 398-401. https://doi.org/10.1006/fstl.2001.0779

[5] Ponce Cevallos, P.A., Buera, M.P. and Elizalde, B.E. (2010) Encapsulation of Cinnamon and Thyme Essential Oils Components (Cinnamaldehyde and Thymol) in $\beta$-Cyclodextrin: Effect of Interactions with Water on Complex Stability. Journal of Food Engineering, 99, 70-75. https://doi.org/10.1016/j.jfoodeng.2010.01.039

[6] Westing, L.L., Reineccius, G.A. and Caporaso, F. (1988) Shelf Life of Orange Oil. Effects of Encapsulation by Spray-Drying, Extrusion and Molecular Inclusion. American Chemical Society, 370, 78-86.

[7] Dolçà, C., Ferrandiz, M., Capablanca, L., Franco, E., Mira, E. and López, F. (2015) Microencapsulation of Rosemary Essential Oil by Co-Extrusion/Gelling Using Alginate as a Wall Material. Journal of Encapsulation and Adsorption Sciences, 5, 121 130. https://doi.org/10.4236/jeas.2015.53010

[8] Kailasapathy, K. (2002) Microencapsulation of Probiotic Bacteria: Technology and Potential Applications. Current Issues in Intestinal Microbiology, 3, 39-48.

[9] Özcan, M.M., Ünver, A., Erkan, E. and Arslan, D. (2011) Characteristics of Some Almond Kernel and Oils. Scientia Horticulturae, 127, 330-333. https://doi.org/10.1016/j.scienta.2010.10.027

[10] Ahmad, Z. (2010) The Uses and Properties of Almond Oil. Complementary Therapies in Clinical Practice, 16, 10-12. https://doi.org/10.1016/j.ctcp.2009.06.015

[11] Oktem, T. (2003) Surface Treatment of Cotton Fabrics with Chitosan. Coloration Technology, 119, 241-246. https://doi.org/10.1111/j.1478-4408.2003.tb00179.x

[12] Klaypradit, W. and Huang, Y.W. (2008) Fish Oil Encapsulation with Chitosan Us- 
ing Ultrasonic Atomizer. LWT-Food Science and Technology, 41, 1133-1139. https://doi.org/10.1016/j.lwt.2007.06.014

[13] Berger, J., Reist, M., Mayer, J.M., Felt, O., Peppas, N.A. and Gumy, R. (2004) Structure and Interactions in Covalently and Ionically Crosslinked Chitosan Hydrogels for Biomedical Applications. European Journal of Pharmaceutics and Biopharmaceutics, 57, 19-34. https://doi.org/10.1016/S0939-6411(03)00161-9

[14] Siso, M., Lang, E., Carreño-Gomez, B., Becerra, M., Otero Espinar, F. and Blanco Mendez, J. (1997) Enzyme Encapsulation on Chitosan Microbeads. Process Biochemistry, 32, 211-216. https://doi.org/10.1016/S0032-9592(96)00064-7

[15] Tsai, M.L., Bai, S.W. and Chen, R.H. (2008) Cavitation Effects versus Stretch Effects Resulted in Different Size and Polydispersity of Ionotropic Gelation ChitosanSodium Tripolyphosphate Nanoparticle. Carbohydrate Polymers, 71, 448-457. https://doi.org/10.1016/j.carbpol.2007.06.015

[16] Lee, S.-T., Mi, F.-L., Shen, Y.-J and, Shyu, S.-S. (2001) Equilibrium and Kinetic Studies of Copper(II) Ion Uptake by Chitosan-Tripolyphosphate Chelating Resin. Polymer, 42, 1879-1892. https://doi.org/10.1016/S0032-3861(00)00402-X

\section{Submit or recommend next manuscript to SCIRP and we will provide best service for you:}

Accepting pre-submission inquiries through Email, Facebook, LinkedIn, Twitter, etc. A wide selection of journals (inclusive of 9 subjects, more than 200 journals)

Providing 24-hour high-quality service

User-friendly online submission system

Fair and swift peer-review system

Efficient typesetting and proofreading procedure

Display of the result of downloads and visits, as well as the number of cited articles

Maximum dissemination of your research work

Submit your manuscript at: http://papersubmission.scirp.org/

Or contact jeas@scirp.org 